\title{
The Pattern, Risk Factors and Clinico-Aetiological Correlate of Tinea Capitis Among the Children in a Tropical Community Setting of Osogbo, South-Western Nigeria
}

Corresponding author: Adeolu O. Akinboro

email:

deolusteve111@yahoo.com mobile:

$+2348136873$

2240

Received $: 1 / 12 / 2011$

Accepted after

revision: $15 / 12 / 2011$

Keywords :

Tinea .capitis, Clinical types, dermatophytes, risk factors

\author{
Adeolu O. Akinboro ${ }^{1}$, Olayinka A. Olasode ${ }^{2}$, Olaniyi Onayemi ${ }^{3}$ \\ ${ }^{1}$ Dermatology Unit, Department of Internal Medicine, LAUTECH Teaching Hospital, and \\ College of Health Sciences, Ladoke Akintola University of Technology,Ogbomoso,Oyo \\ State, Nigeria \\ ${ }^{2}$ Department of Dermatology and Venereology, Obafemi Awolowo University Teaching \\ Hospital Complex, and College of Health Sciences,Obafemi Awolowo University, Ile - Ife, Osun \\ State, Nigeria \\ ${ }^{3}$ Department of Dermatology and Venereology, Obafemi Awolowo University Teaching \\ Hospital Complex, and College of Health Sciences, Obafemi Awolowo University, Ile - Ife, Osun \\ State, Nigeria
}

Background and study aim: Tinea. capitis is an important infective dermatologic disease of worldwide distribution among children. Its frequency is increasing especially in the developing world, and has become an endemic disease in some places. To determine the prevalence, the risk factors, pattern and clinico - aetiological correlate of Tinea capitis among the children in Ilie community.

Patients and Methods: A total of 370 children aged 5-16 years; 185 with Tinea capitis as subjects and 185 relatively healthy children as controls. Multistage sampling method was employed, and house to house survey for Tinea capitis was conducted. The diagnosis of Tinea capitis was made and scrapings were obtained for microscopy and culture.

Results: The mean age was $7.31+2.52$ years for the subjects and $7.40 \pm 2.43$ years for the controls. The mean age of onset of $T$. capitis was $5.2 \pm 2.039$ years. The prevalence of $T$. capitis in Ilie Community was $43.5 \%$. Contact with animals, soil and individuals with $T$. capitis were the prevalent risk factors for

\section{INTRODUCTION}

Ringworm which can also be simply referred to as Tinea, is an infectious fungal disease of the skin and its integuments.[1] It is one of the superficial infections of worldwide distribution but of extreme prevalence in the humid regions of the world. [1] Tinea capitis ( $T$. capitis) is a public health problem in Nigeria though not
T. capitis. Large family size did contribute but not significantly to the spread of Tinea. Also, history of atopy did correlate but not significantly with disease chronicity. A total of 120 isolate representing 7 different dermatophytes including; T. metangrophytes $(67.5 \%)$ as the leading organism were isolated. There was no case of mixed infection. Other isolates include $T$. tonsuran (13.3\%), $T$. rubrum (10.8\%), M. aodounii (2.5\%), $M$. gypseum (2.5\%), T. violaceum (1.7\%), $T$. soudanence $(1.7 \%)$. Trichophyton metangrophytes was the most frequent organism causing the predominant non inflammatory type of T. capitis (Gray patch and Black dot type) though not exclusively among children age group 5-8 years and 9-12 years, followed by $T$. effectively reduce contact with the sources of infection.

Conclusion: Tinea capitis remains an endemic disease reaching variable epidemic proportion in some populations as seen in Ilie among the children. The non - inflammatory type (GPTC, BDTC) were the prevalent clinical types of $T$. capitis in Ilie. tonsurans. A bold step must be taken to

a reportable disease. Like other infectious diseases, it has its heavy toll on children between ages of 4 and 14 years because of frequent body contact that occur among children. $[2,3]$ Gugnani and Njoku-obi [3]had earlier attributed the public health problems caused by dermatophytosis in Nigeria to the warm humid climate, crowded living, poor 
sanitary conditions of the majority of the populace, and same has been enhancing the spread of the disease. In the past decades, the disease remained endemic in Nigeria, largely because of lack of information on its prevalence and the absence of necessary control measures in place [4]. The ringworm of the head is a public place ill: in the schools and other public places where children are found and have continue to be an issue of concern among parents and teachers that cares.

The epidemiology of $T$. capitis varies from place to place [5]. These variations range from changing prevalence, shifting agents, to seasonal escalations. Fathi et al attributed this variation to people's habits, lifestyle, and standards of hygiene, climate conditions and levels of education. [5]

Previous works on $T$. capitis in our environment placed emphasis on prevalence and implicated aetiological agents, clinical types were not properly defined. Therefore, findings from a community based study of $T$. capitis was aimed at bridging existing gaps, proffer solution to lingering wildfire and continuous threat of $T$. capitis among children and may serve as an incentive to a more comprehensive approach to the management of $T$. capitis and generate data for further studies.

\section{PATIENTS AND METHODS}

This study was conducted in Ilie community, a village in Olorunda Local government headquarters in Osogbo, the capital of Osun State, Nigeria. Ilie is located in the tropical rain forest belt of South-Western part of Nigeria and is about 500 kilometers from Abuja the capital city of Nigeria. Geographically Ilie lies approximately on latitude $40^{\circ} \mathrm{N}$ of equator and longitude $7.34^{\circ} \mathrm{E}$ of Greenwich meridian.

Ilie is an organized community outreach centre of Ladoke Akintola University Teaching Hospital, where medical students undergo their community medicine posting. Vegetation in Ilie is a mixture of Savannah and semi-tropical forest. There are two distinct seasons; the wet and the dry seasons. The former occurs between April and October, while the later takes place from November to March.

Largely the community is an agrarian and fishing community, other occupations of the people include trading, cloth dying and wood carving. The community is an example of typical African setting and settlement; the dwellers have large and extended family .Children and adults are living together in compounds with household numbers varying from two to five per compound. Houses are built mostly with mud. Only very few houses were cemented and were built years past and presently were dilapidated and in a state of disrepute. Also, domestic animals and pets are kept in very close association with humans.

The people are mainly Yorubas, but other ethnic groups including Ibos, Hausas, and some minority group that work as manual labourers, serving the need of the community.

From population projection of 2006 national census, about 5500 people are currently living in Ilie. Population growth rate was put at $2.9 \%$ per annum. The estimated under 15 years $(44 \%$ of Nigeria population) population was projected at 2,420 by year 2009 .

The social amenities in the community include post office, police post, electricity, pipe borne water and a community health centre. Community dermatology services are grossly lacking. Only the parents that filled informed consent form had their children recruited into the study. A systematic community based epidemiological study of Tinea capitis infection has not been conducted in the area.

Study design: Cross-sectional study.

STUDY POPULATION: Three hundred and seventy children were recruited. One hundred and eighty five children with $T$. capitis and 185 sex matched children without any chronic or severe disease as control. The subjects and control group were recruited between August and December 2010.

Selection criteria for patients and controls: Children with symptoms or signs suggestive of $T$. capitis, resident of Ilie, whose parents filled the consent form and aged 5 to 16years with voluntary intention to participate in the study, were recruited. The inclusion criteria for contols were the same except that, they were without $T$. capitis.

Exclusion criteria for patients and controls: All non - Ilie's residents and those whose parent's refused to sign the informed consent .

Clinical Survey for Tinea capitis: The purpose and benefits of the study were explained to the parents and their children in the local Yoruba language. Survey for T. capitis was done in the evening when parents and children had returned back to their homes from school and farm.

Akinboro et al., Afro-Egypt J Infect Endem Dis 2011; 1 (2):53-64

www.mis.zu.edu.eg/ajied/home.aspx 
Multistage sampling method, comprising of successive random sampling was employed. Sixteen communities were randomly selected from the thirty two communities in Ilie village. From the randomly selected community, compounds were randomly recruited into the study. Then from the selected compounds houses were recruited. Compound with two houses had one house randomly selected; two out of three, three out of four, four out of five houses, and five out of six houses were also selected randomly for inclusion into the study.

Children from selected houses had the survey questionnaire self administered by the investigators. The questionnaire focused on socio-demographic characteristics like age, sex, and child's education level, parent's occupation, number of children in the family and average monthly income, race and religion. Clinical history such as age at onset of $T$. capitis, duration of $T$. capitis, history of contact with animal, soil, individuals with $T$. capitis, and place of barbing were recorded. All the children in the selected houses had all areas of their scalp thoroughly examined for clinical types of $T$. capitis and lymphadenopathy. Diagnosis of clinical types was also made as seen among the children include; Scaly annular patch, inflammatory black dot pattern, Inflammatory T. capitis (kerion), Inflammatory T. capitis (Favus), and inflammatory pustular type.

Sample Collection and laboratory processing: The affected area of the head was cleaned with alcohol, hairs and scales were collected into dry, clean envelope for mycological examination using the technique described by Fathi et al. [3]. The hair scrapping was transported from the field in a dry clean envelope. Identification of all specimens taken from the scalp was done by direct microscopy with $10 \% \mathrm{KOH}$, The scrapings and the pieces of hair were plated out immediately as soon as investigator arrived from the field on daily basis separately on culture media. Slide culture technique was also used. The dermatophyte specific Potatoe agar was used. Each of the culture plates were incubated at $27^{\circ} \mathrm{C}$ for 4 weeks and then macro and micro morphological studies of cultured colonies was done for the presence of dermatophytes.

\section{STATISTICAL ANALYSIS:}

Data was analyzed using Statistical Programme for Service Solution 16.0 (SPSS Chicago Inc., IL, and U.S.A.).The socio-demographic variables of the patients were summarized using the
Student's t-test for numeric variables and Chi square tests for categorical variables. Clinical variables such as age at onset, duration of $T$. capitis, family and atopy history, close contact with soil, animals, and individual with $T$. capitis. Other clinical variables like alopecia, scaling, pruritus, and lymphadenopathy were also summarized using the Student's t-test for numeric variables and Chi square tests for categorical variable as applicable. The pattern of animal contact was represented with bar chart .

\section{RESULTS}

The mean age was $7.31 \pm 2.52$ years for the children with $T$. capitis and $7.40 \pm 2.43$ years for the apparently normal children recruited into the study as controls. There was no significant difference between the age of both group statistically $(t$ test $=0.74 \mathrm{df}=278, \mathrm{p}=0.67)$. The range and mode were 5-16 and 5 years respectively for both $T$. capitis group and control. (Table 1)

A total of 425 children were randomly recruited and examined before the sample size was completed. Overall prevalence of $T$. capitis in this population was $43.53 \%$. Prevalence was highest among the age group 5- 8 years ,139 $(57.43 \%)$ followed by age group 9- 12 years, 35 $(42.12 \%)$ and least among age group 13-16 years, 89 (20.94\%). Tinea Capitis was prevalent among the boys than the girls. The overall prevalence among the boys was 131 (30.82\%), and among the girls were $54(12.70 \%)$. The highest prevalence was recorded among boys 5 8 years, 91(37.6\%), the least was among girls 912 years, $6(6.38 \%)$. $T$ capitis was not recorded among girls 13 - 16 years( Table 1).

Table (1) also shows the distribution of children per families' of $T$. capitis and the control groups. Most of the subjects (T. capitis group) came from a larger family with many children than the control. The mean number of children per family for the subjects and controls were, $4.81 \pm$ 2.012 and $4.63 \pm 2.210$ respectively. The most frequent number of children encountered in the study per family was 5 for the subjects, and was 4 for the controls. The number of children per family for the subjects ranged from $1-15$, for the controls it ranged from 1- 12. However, this difference was not statistically significant, $(t=$ $0.787, \mathrm{df}=368, \mathrm{p}=0.155$ ).

T. capitis was rare before the age of one year, only $4(0.9 \%)$ of the subjects had the infection before one year. Most of the subjects had $T$.

Akinboro et al., Afro-Egypt J Infect Endem Dis 2011; 1 (2):53-64 www.mis.zu.edu.eg/ajied/home.aspx 
capitis by the age of 6 year. The mean age of onset of T. capitis was $5.2 \pm 2.039$ years and the most frequent age of onset was 5 years. The duration of $T$ capitis among children was $0.6 \pm 1.031$ with a range of $0.1-13$ years. , 99(49.1\%) children have had T. capitis for about one year. Also, 52 children $(28.1 \%)$ had T.capitis for at least 2 years, while 14 (7.6\%), 9 (4.9\%), 11 (5.9\%) and $4(2.2 \%)$ had T. capitis for at least 3 , 4,5 and 6 years respectively. Only 4 (2.2\%) of $T$. capitis population had the infection recurrently for more than 8years.

There was no statistically significant difference between children with $T$. capitis and the control group in terms of educational attainment (Table 2). Majority of the pupils, T. capitis and control group were in the primary school, 105 (56.8\%) vs $94(50.8 \%)$ respectively. This was closely followed by children in pre-school age, 68 (36.8\%) vs $74(40.0 \%)$ respectively for both $T$. capitis and control group. Only a few of the children randomly recruited were in the secondary school at the time of survey, 11 (5.9\%) vs $17(9.2 \%)$ for $T$. capitis group and control group respectively $\left(\mathrm{X}^{2}=75.474, \mathrm{df}=2, p\right.$ $=0.000$ ) Whereas, the entire pupils in the control group were enrolled in one form of formal education or the other, one child, $(0.5 \%)$ of the Tinea group had no form of education. Statistically, there was no significant difference in the educational attainment of both groups. (X $\left.{ }^{2}=3.147 \mathrm{df}=3, \mathrm{p}=0.344\right)$ ( Table 2).

The two groups however differ significantly in terms of occupation and religion. While majority of the parents of children with $T$. capitis group were predominantly farmers and fisher men, the control group were largely civil servants and men that were self employed in trades such as road side mechanics, drivers, patent medicine store operators and the likes. Statistically this difference was found to be significant. $\left(\mathrm{X}^{2}=\right.$ 99.219, $\mathrm{df}=2, p=0.000$ ).

From Table (2), children with T. capitis were likely to have farmers and fishermen as parent, while the parents of the control population were likely to be civil servants and self employed individuals.

The Average income of the families of the subject and controls were evaluated. Most families in the $T$ capitis group, 140 (76.1\%) earn less than N5 000; 00(\$33.00) per month which is much below the Nigerian minimum wage, while income among the parents of the children in the control group spread across the entire income bracket. The average family income per month for the subjects was N8 $260(\$ 52.00) \pm 11$ $749(\$ 74.36)$, and controls was N16 $880: 00(\$ 106.83) \pm 14$ 513:00(\$91.85). The range of income per month for the subjects and control group was N1, 000 - N 50000 (\$6.3.00- 316.00) and N3 000 - N 60000 (\$18.98 - 379.74) respectively. The difference in the family incomes was found to be statistically significant. $(t$ test $=-6.269, \mathrm{df}=368, \mathrm{p}=0.000)($ Table 2$)$.

Assessment was made for the possible risk factors for Tinea among the children. Majority of the children with $T$. capitis had significant animal contact, $166(89.7 \%)$ than the children in the control group, 105 (56.8\%). The existed difference was statistically significant. $\left(\mathrm{X}^{2}=\right.$ $51.316 \mathrm{df}=1, p=0.000$ ). Meanwhile, figure( 1 ) shows the pattern of animal contact among the children with $T$. capitis and controls. The predominant animal contacted was goat among both group; $125 / 185$ and 74/185 respectively. Frequent contact with goat and other animals being kept for commercial purposes was highest among children with $T$. capitis than control group (Goat and sheep: $26 / 185$ and 2/185; sheep alone 5/185 and 2/185 respectively).

Contact with pets like dog and cat were frequent among controls than the children with $T$. capitis (14/185 and 8/185 respectively ).

Contact with soil was also more common among children with $T$. capitis than control $156(84.3 \%)$ vs $14(7.6 \%)$ respectively. The difference was statistically signifacnt, $\left(\mathrm{X}^{2}=2.194, \mathrm{df}=1, p=\right.$ 0.000). Also frequent among children with $T$. capitis than the control was the positive history of previous contact with individual that had ringworm, 146 (78.9\%) vs 38 (20.5\%) respectively. The observation was also found to be significant, $\left(\mathrm{X}^{2}=1.261\right.$, $\left.\mathrm{df}=1, p=0.000\right)$. Household contact was significantly higher than contact in the classroom. $\left(\mathrm{X}^{2}=72.339, \mathrm{df}=1, p=\right.$ $0.000)$. One hundred and thirty five $(73.0 \%)$ of the children with $T$. capitis use various available village barbers while 30 (16.2\%), either weaved or barb their head at home. The difference found between self barbing and public barbing was statistically significant, $\left(\mathrm{X}^{2}=8.096, \mathrm{df}=1, p=\right.$ 0.017). (Table 3)

History suggestive of various atopic diathesis was also commoner among children with $T$. capitis than controls, 54 (29.45\%) vs 4 (2.2\%), statistically the difference was also significant. $\left(\mathrm{X}^{2}=51.116\right.$, df $\left.=1, p=0.000\right)$. (Table 3) Rhinitis was the prevalent atopy suggestive 
symptom $45 / 54(83.3 \%)$, this was followed by Vernal conjunctivitis 4/54 (7.45\%), Atopic dermatitis $3(5.5 \%)$, and Asthma 2 (3.7\%)(Table 3).

Family history of $T$. capitis in the parents of children with $T$. capitis infection and the control was present in 45/185 (24.3\%) and 4/185 (2.2\%) of the control. Statistically, the difference between the two groups was significant $\left(\mathrm{X}^{2}=\right.$ 39.543 , df $=1, p=0.000$ ). However, there was an non-significant positive correlation between history of atopy and the duration of T. capitis in this study. $(r=0.024, p>0.05)$ (Table 3$)$

The study examined the pattern of symptoms found among the recruited children, scalp scaling was the predominant symptom found among $179 / 185(96.8 \%)$ more than as found in the controls, $12 / 185(6.3 \%)$. The difference was found to be statistically significant $\left(\mathrm{X}^{2}=\right.$ 346.754, df $=1, p=0.000$ ) (Table 3) .Scalp pruritus followed by scaling as the second most frequently encountered symptom in this study among children with $T$. capitis than among the controls and the existed difference in this pattern of presentation was found to be statistically significant, 161/185 (87.0\%) vs 27/185 (14.6\%), $\left(\mathrm{X}^{2}=3.018, \mathrm{df}=1, p=0.000\right)($ Table 3$)$.

However, hair loss (alopecia) was present both as symptom and examination finding significantly among children with $T$.capitis than the controls, $139 / 185(75.1 \%)$ vs $0(0.0)\left(\mathrm{X}^{2}=222.641\right.$, df $=1$, $p=0.000)$. Alopecia was predominantly patchy and non - scarring 134 (96.4\%) than patchy scarring form which was present in $5(3.6 \%)$ (Table 3 ).

Adenopathy was also significantly present among children with $T$. capitis than control ,47
/185 (25.4\%) vs 5/185 (2.7\%), $\left(\mathrm{X}^{2}=41.978\right.$, df $=1, p=0.000)$. Fourty four $(23.78 \%)$ children had lymphadenopathy at the posterior cervical area and $3 / 47(6.38 \%)$ had it in the post auricular area( Table 3$)$.

The various clinical types of T.capitis were examined for; the non-inflammatory form of $\mathrm{T}$. capitis was prevalent: "Gray patch" Tinea capitis (GPTC) 86/185 (46.5\%), "Black dot" Tinea capitis (BDTC) 78(42.2), Seborrheic dermatitis type Tinea capitis (SDTC) $18(9.7 \%)$, and the pustular inflammatory type $3(2.2 \%)$. No case of Kerion or Favus was recorded (Fig 2,3,4\&5)

Attempt was made to correlate clinical type of $T$. capitis with species of organism responsible. $T$. metangrophyte was responsible for noninflammatory $T$. capitis: BDTC and GPTC and SDTC .There was no clear cut correlation between dermatophytes and clinical types $(\mathrm{r}=$ $0.025, \mathrm{p}=0.567$ ) .

The scaling and hairs from children's scalp were obtained for microscopy and culture. Scrapping was only possible and obtainable from 179 children. One hundred and sixty two samples were positive for fungal element microscopically while 17 samples showed no growth. Culture confirmed growth of dermatophytes only in 120 samples. Isolated dermatophytes represented 2 genera; Trichophyton and Microsporon, and 8 different dermatophytes including Trichophyton metangrophytes as the leading organism isolated. There was no case of mixed infection. Other isolates of this study include $T$. tonsuran, T.rubrum, T.violaceum, T. soudanence, Microsporon auodounii Microsporum gypseum. Trichophyton metangrophytes was the most frequent organism causing infection in children, followed by $\mathrm{T}$. tonsuran as shown in Table( 4). 
Table (1): General Characteristics of Children with Tinea capitis and the Controls

\begin{tabular}{|c|c|c|c|c|}
\hline Variables & & \multicolumn{2}{|c|}{ T. capitis group } & Control \\
\hline \multicolumn{5}{|c|}{ Age of participants(years) } \\
\hline $\begin{array}{c}\text { Mean } \pm \text { SD } \\
\text { Mode } \\
\text { Range }\end{array}$ & & \multicolumn{2}{|c|}{$\begin{array}{c}7.31 \pm 2.52 \\
5 \\
5-16\end{array}$} & $\begin{array}{c}7.40 \pm \frac{ \pm}{5} 2.43 \\
5-16\end{array}$ \\
\hline \multicolumn{5}{|c|}{ Number of children per family } \\
\hline $\begin{array}{c}\text { Mean } \pm \text { SD } \\
\text { Mode } \\
\text { Range }\end{array}$ & & \multicolumn{2}{|c|}{$\begin{array}{c}4.81 \pm 2.012 \\
5 \\
1-15\end{array}$} & $\begin{array}{c}4.63 \pm 2.210 \\
4 \\
1-12\end{array}$ \\
\hline \multicolumn{5}{|c|}{ Mean age at onset of $T$. capitis(years) } \\
\hline $\begin{array}{c}\text { Mean } \pm \text { SD } \\
\text { Mode } \\
\text { Range }\end{array}$ & & \multicolumn{2}{|c|}{$\begin{array}{c}5.2 \pm 2.039 \\
5 \\
1 \text { month }-11 \text { years }\end{array}$} & \\
\hline \multicolumn{5}{|c|}{ Duration of Tinea capitis(years) } \\
\hline $\begin{array}{c}\text { Mean } \pm \text { SD } \\
\text { Mode } \\
\text { Range }\end{array}$ & & \multicolumn{2}{|c|}{$\begin{array}{c}0.6 \pm 1.031 \\
1 \\
\text { 1month -13year }\end{array}$} & \\
\hline \multicolumn{5}{|c|}{ Age and Sex Prevalence of T. capitis } \\
\hline \multirow[t]{2}{*}{ Age in years } & Number examined & \multicolumn{2}{|c|}{ Number infected(prevalence) } & Total(prevalence) \\
\hline & & Male & Female & Total $(\%)$ \\
\hline $5-8$ & 242 & $91(37.60)$ & $48(19.83)$ & $139(57.43)$ \\
\hline $9-12$ & 94 & $29(30.85)$ & $6(6.38)$ & $35(37.23)$ \\
\hline $13-16$ & 89 & $11(12.35)$ & $0(0.0)$ & $11(12.35)$ \\
\hline Total & 425 & $131(30.82)$ & $54(12.70)$ & $185(43.53)$ \\
\hline
\end{tabular}

Table (2): Educational attainment, occupation and religion, ethnicity, and average family income per month distribution of patients and controls

\begin{tabular}{|c|c|c|}
\hline Educational attainment* & Tinea capitis group $(\mathrm{N}, \%)$ & Control group $(\mathrm{N}, \%)$ \\
\hline $\begin{array}{l}\text { None } \\
\text { Pre-school } \\
\text { Primary } \\
\text { Secondary }\end{array}$ & $\begin{array}{c}1(0.5) \\
68(36.8) \\
105(56.8) \\
11(5.9) \\
\end{array}$ & $\begin{array}{c}0(0.0) \\
74(40.0) \\
94(50.8) \\
17(9.2) \\
\end{array}$ \\
\hline $\begin{array}{l}\text { Occupation** } \\
\text { Predominantly farming } \\
\text { Predominantly fishing } \\
\text { Other forms of self employment } \\
\text { Unemployed } \\
\text { Civil servants }\end{array}$ & $\begin{aligned} & 130(70.3) \\
& 14(7.6) \\
& 19(10.3) \\
& 0(0.0) \\
& 22(11.9) \\
&\end{aligned}$ & $\begin{array}{c}7(3.8) \\
0(0.0) \\
104(56.2) \\
0(0.0) \\
74(40.0)\end{array}$ \\
\hline $\begin{array}{l}\text { Religion*** } \\
\text { Christianity } \\
\text { Islam } \\
\text { Traditional }\end{array}$ & $\begin{array}{c}28(15.1) \\
157(84.9) \\
0(0) \\
\end{array}$ & $\begin{array}{c}102(55.1) \\
77(41.6) \\
6(3.2) \\
\end{array}$ \\
\hline $\begin{array}{l}\text { Ethnicity**** } \\
\text { Yoruba } \\
\text { Hausa } \\
\text { Igbo } \\
\text { Others }\end{array}$ & $\begin{array}{l}183(98.9) \\
0(0.0) \\
0(0.0) \\
2(1.1) \\
\end{array}$ & $\begin{array}{l}176(95.1) \\
6(3.2) \\
3(1.6) \\
0(0.0) \\
\end{array}$ \\
\hline $\begin{array}{l}\text { Average income per month(Naira)***** } \\
0-5000 \\
5,001-10,000 \\
10,001-20,000 \\
20,001-50,000 \\
>50,000 \\
\text { Mean } \pm \text { SD } \\
\text { Range }\end{array}$ & $\begin{array}{c}140(76.1) \\
17(9.2) \\
13(7.1) \\
14(7.6) \\
0(0.0) \\
8,260 \pm 11,749 \\
1,000.00-50,000\end{array}$ & $\begin{array}{c}56(30.3) \\
31(16.8) \\
52(28.1) \\
43(23.2) \\
3(1.6) \\
16,880 \pm 14,513 \\
3,000-60,000\end{array}$ \\
\hline
\end{tabular}


Table (3): Comparism of some risk factors, clinical history and examination findings: children with Tinea. capitis and controls.

\begin{tabular}{|c|c|c|c|c|c|}
\hline \multirow[t]{2}{*}{ Clinical variables } & \multicolumn{2}{|c|}{ Tinea capitis group N( \%) } & \multicolumn{2}{|c|}{ Control group (N \%) } & \multirow[t]{2}{*}{$\mathrm{X}^{2}$} \\
\hline & Yes & No & Yes & No & \\
\hline Animal contact & $166(89.7)$ & $19(10.3)$ & $105(56.8)$ & $80(43.2)$ & $51.316^{*}$ \\
\hline Soil contact & $156(84.3)$ & $29(15.7)$ & $14(7.6)$ & $171(92.4)$ & $2.194 *$ \\
\hline Human contact & $146(78.9)$ & $39(21.1)$ & $38(20.5)$ & $147(79.5)$ & $1.261 *$ \\
\hline Atopy History & $54(29.8)$ & $131(68.5)$ & $4(2.2)$ & $181(97.3)$ & $51.116^{*}$ \\
\hline Family history & $45(24.3)$ & $140(75.7)$ & $4(2.2)$ & $181(97.8)$ & $39.543^{*}$ \\
\hline \multicolumn{6}{|l|}{ Clinical History } \\
\hline Scalp pruritus & $161(87.0)$ & $24(13.0)$ & $27(14.6)$ & $158(85.4)$ & $1.942 *$ \\
\hline Scalp scaling & $179(96.8)$ & $6(3.2)$ & $12(6.3)$ & $173(96.6)$ & $3.018 *$ \\
\hline Adenopathy & $47(25.4)$ & $138(74.6)$ & $5(2.7)$ & $180(97.3)$ & $41.978^{*}$ \\
\hline Alopecia & $139(75.1)$ & $46(24.9)$ & $0(0.0)$ & $185(100.0)$ & $2.226 *$ \\
\hline \multicolumn{6}{|l|}{ Type of Atopy } \\
\hline Rhinitis & \multirow{4}{*}{\multicolumn{2}{|c|}{$\begin{array}{c}45(83.3) \\
2(3.7) \\
3(5.5) \\
4(7.4)\end{array}$}} & \multirow{4}{*}{\multicolumn{2}{|c|}{$\begin{array}{l}2(3.7) \\
0(0.0) \\
0 .(0.0) \\
0(0.0)\end{array}$}} & \\
\hline Asthma & & & & & 2.331 \\
\hline Dermatitis & & & & & \\
\hline Conjuctivity & & & & & \\
\hline Contacts & \multirow{6}{*}{\multicolumn{2}{|c|}{$\begin{array}{c}135(73.0) \\
14(16.7) \\
155(83.3) \\
134(16.7) \\
0(0)\end{array}$}} & \multirow{6}{*}{\multicolumn{2}{|c|}{$\begin{array}{c}14(7.6) \\
27(14.6) \\
30(16.2) \\
49(26.5) \\
2(0.1)\end{array}$}} & \\
\hline Family member & & & & & $72.339 *$ \\
\hline Class member & & & & & \\
\hline Barbing saloon & & & & & $8.096^{*}$ \\
\hline Home Barbing & & & & & \\
\hline Weaving & & & & & \\
\hline
\end{tabular}

$* \mathrm{df}=1, \mathrm{p}<0.001 \mathrm{~N}=$ number

Table (4): Distribution of dermatophytes isolated according to sex among the children in Ilie Community

\begin{tabular}{|l|c|c|c|}
\hline \multicolumn{1}{|c|}{ Species } & \multicolumn{3}{c|}{ Isolates according to sex } \\
\cline { 2 - 4 } & Total (\%) & Male & Female \\
\hline Trichophyton mentagrophytes & $81(67.5)$ & 67 & 14 \\
Trichophyton tonsuran & $16(13.3)$ & 10 & 3 \\
Trichophyton rubrum & $13(10.8)$ & 10 & 1 \\
Microsporum audouinii & $3(2.5)$ & 2 & 1 \\
Microsporium gypseum & $3(2.5)$ & 2 & 0 \\
Trichophyton violaceum & $2(1.7)$ & 2 & 0 \\
Trichophyton soudanense & $2(1.7)$ & 2 & $25(20.83)$ \\
\hline
\end{tabular}

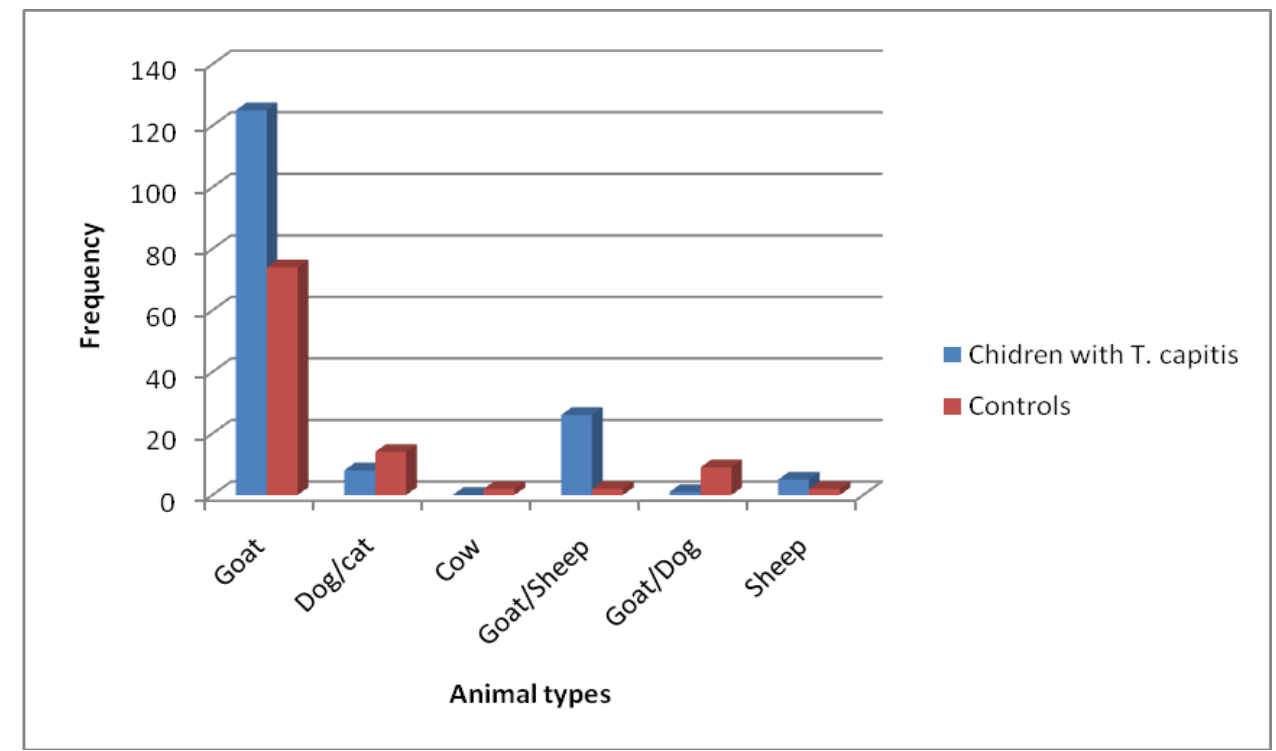

Figure (1): shows the pattern of animal contact: patients and controls

$$
\mathrm{X}^{2}=51.316, \mathrm{df}=1, \mathrm{p}<0.001
$$

Akinboro et al., Afro-Egypt J Infect Endem Dis 2011; 1 (2):53-64 www.mis.zu.edu.eg/ajied/home.aspx 


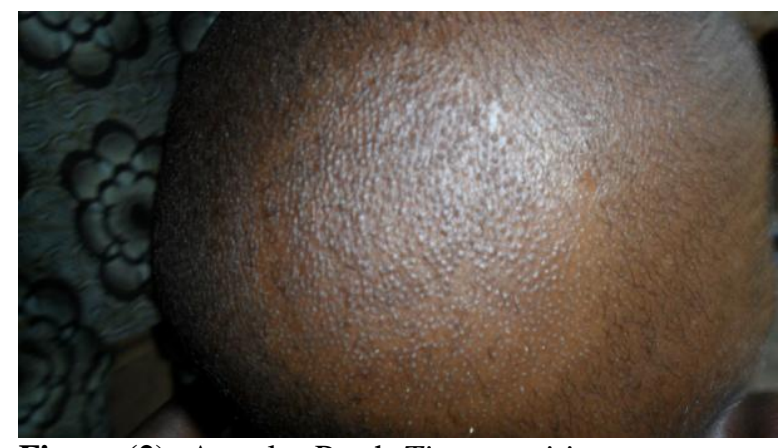

Figure (2): Annular Patch Tinea capitis

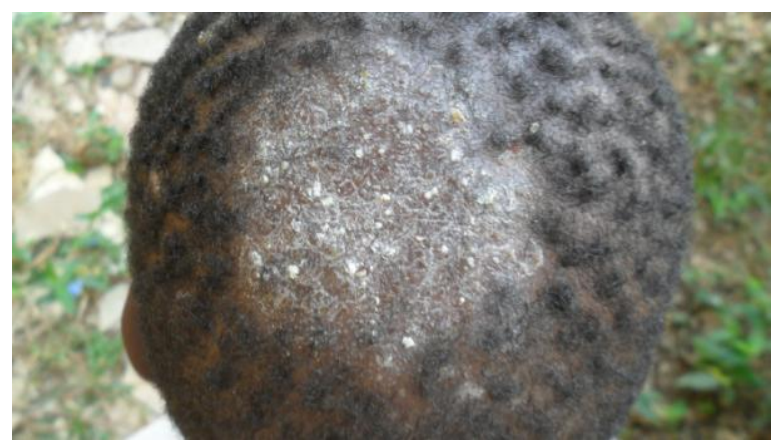

Figure (3): Infected Annular Patch Tinea capitis

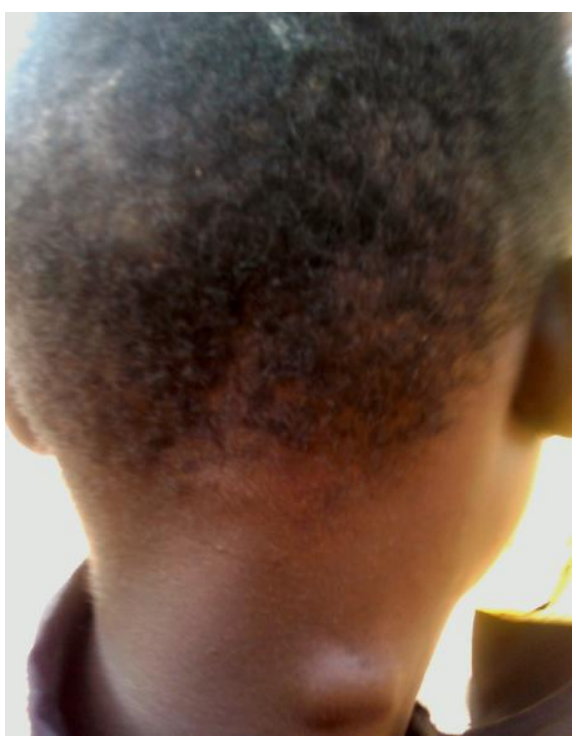

Figure (4): A child with Tinea capitis and posterior cervical lymphadenopathy.
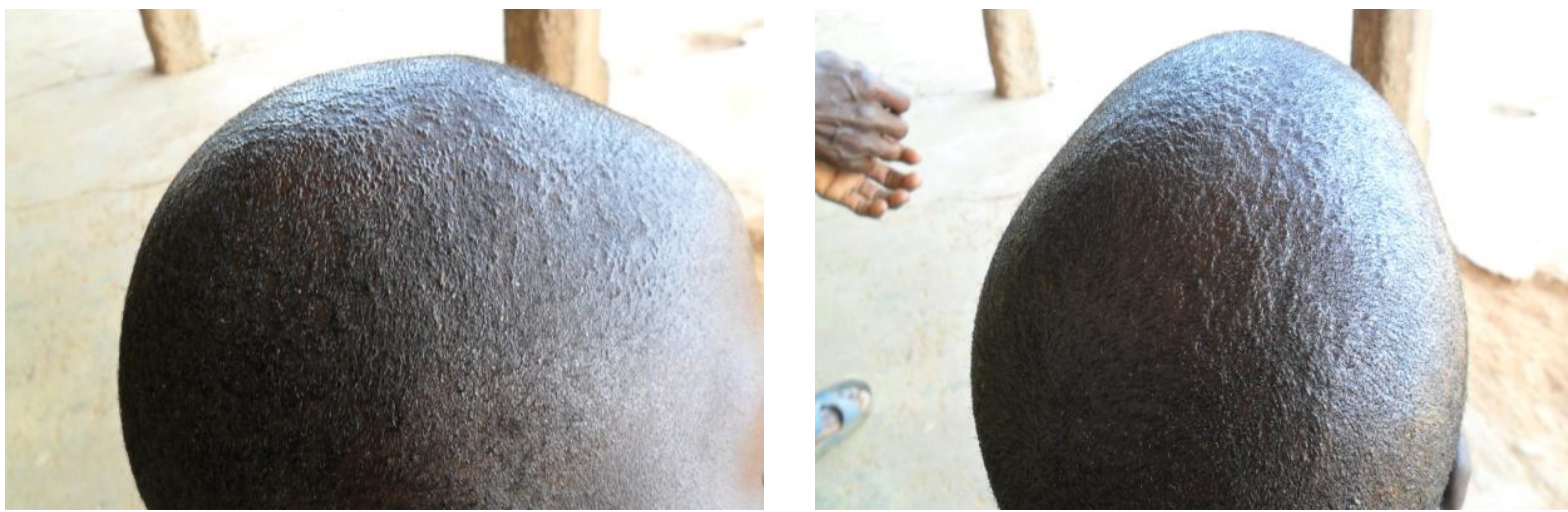

Figure (5): Black dot type Tinea capitis
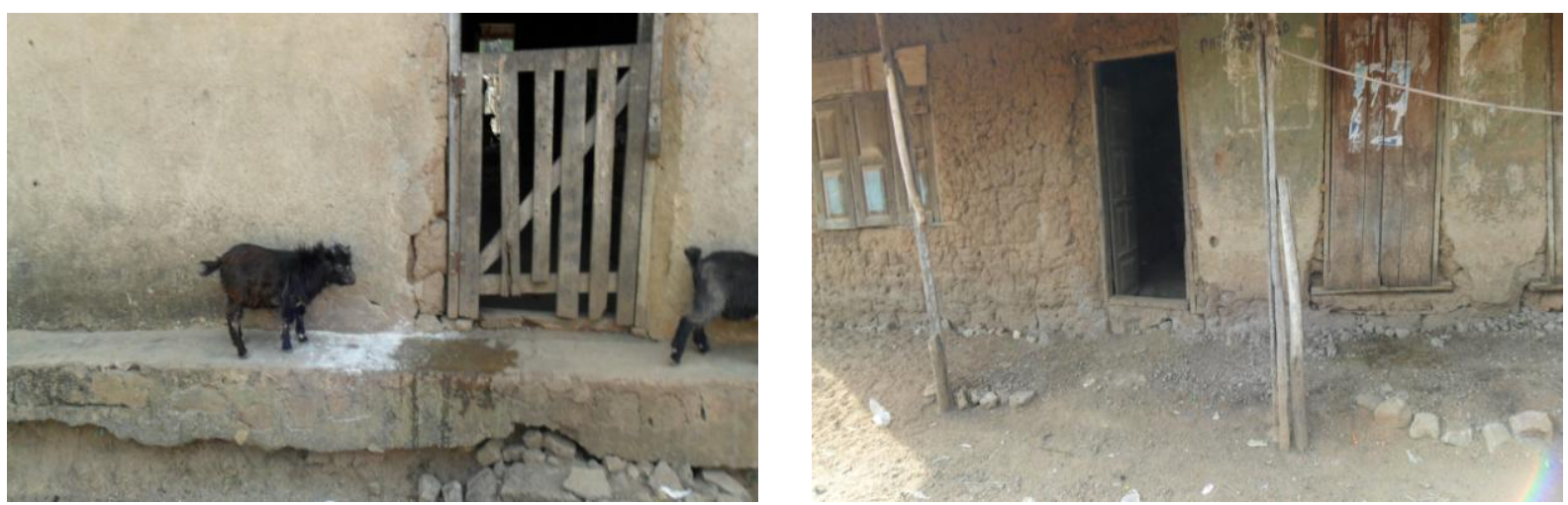

Figure (6) :Dilapidated building, uncemented floor and dermatophyte infected animals living in close contact with humans

Akinboro et al., Afro-Egypt J Infect Endem Dis 2011; 1 (2):53-64 www.mis.zu.edu.eg/ajied/home.aspx 


\section{DISCUSSION}

The overall prevalence of T.capitis in this study was $43.5 \%$. This prevalence rates is widely in excess of previously recorded prevalence of $4 \%$ to $30 \%$ described among school children in the Western and Southern part of Africa. [6, 7] Soyinka [8] recorded a higher prevalence of $55 \%$ in a population based study and they thought there was an epidemic of $T$. capitis among school pupils. Tinea Capitis has been known to reach epidemic proportions among school children. The observed prevalence in this study is higher than $14.05 \%$ recorded by Ajao and Akintunde in Ile- Ife [9] and similarly prevalence was highest among boys (30.82\%) compared to girls $(12.7 \%)$.

In the past decades, several studies have concluded that $T$. capitis is an important dermatologic condition widely distributed throughout the world, more importantly among children. Its frequency is increasing, and aetiological agents vary from one geographic location to another. Several other Nigerian [3, 4, $8,10,11,12,13]$ and international studies [14, 15] had documented differences in occupation, parent income as a significant risk factors for $T$. capitis as shown in this study. Parents of children with $T$. capitis in this study were more likely to be predominantly farmers and fishermen, while those of controls were predominantly office workers or self employed in other forms of trade. This is in line with epidemiological reasoning that, low income earning or poverty, malnutrition and general poor social conditions experienced by subsistent farmers, coupled with unlimited exposure to potential sources of infections such as contaminated soil and animals highly predisposed children in Ilie to T.capitis. The strong link between animals and dermatophyte had been previously documented by Abdulkadir [16], Ameh and Okolo [17] in the Northern states of Nigeria.

The study also found that children in Ilie community live in close contact with animals (predominantly goat, sheep and dogs) which were being kept for business, family food supply and hunting purposes. Abdulkadir [16] had earlier confirmed the enzootic ringworm of horses, dogs, and livestock as common source of sporadic infection among owners or their care takers which might include the owner's children. Animal type ringworm was also viewed by Macura as an occupational hazard for farmers and pet keepers [18] .Study from Sokoto state of
Nigeria where livestock and pet domestication was found as a common practice in households, had suggested domestic animals as important reservoir of tinea. Direct or indirect contact with fungus contaminated objects of livestock rearing like dung, fencing, halters, rope, harness and grooming brushes were found as extremely important in the natural dissemination of the disease.[17]

Other authors in the region had observed that Tinea transmission was encouraged by poor living unsanitary condition with overcrowding [3]. Soil in the homes of livestock keepers and playground has been viewed by several authors as containing fungal element that dropped from the body of infected animals or primarily a geophillic agent [19]. The high frequency of $T$. capitis among children had therefore been linked to intense close contact among children especially at play grounds and at home. This study showed that contact were more intense at home amongst family members and neighbors than in the classroom, this is understandable because pupils spend few hours in the school, and most hours are spent at home and neighborhood play grounds.

In addition, most children with $T$. capitis came from large families (> 4 children), this seems not significant enough as a sole factor that could risk the children and sustain the infection in the community. This observation is similar to the former findings of Ajao et al. in Ile - Ife. [9]

Like other previous studies $[3,4,8,10,11,12,13]$ boys were predominantly infected than girls, with a ratio of 2.4: 1 which was greater than 1.8: 1 recorded by Kalla et al.[20] in India but lower than a high ratio 5: 1 recorded by Gugnani and Njoku-Obi in South-eastern Nigeria.[3] The mean age of infection with dermatophyte was $7.31 \pm 2.52$ years, which is closer to the observation of other workers $[8,21]$. The most frequent age group affected was $5-8$ years with most likely age of infection being 5 years. Gugnani and Njoku-Obi recorded age group 3- 7 years in their study [3]. Ayanbimpe et al [21] also documented the highest rate of infection in the age bracket $10-14$ years; this was closely followed by similar age grouped 5-8 years which was observed in this study. Tinea capitis was not seen among girls older than 13 year. Soyinka and others had adduced this high prevalence of $T$. capitis among the boys to continuous and sustained exposure to infective agents and close body contact at the play ground, and the fact that most boys visit the same set of barbers that 
harbor infective agents on their barbing equipment $[8,12,21]$.Furthermore, most of the girls older than 13 years may prefer to weave their hair rather than visiting barber's shop, they practice better hair and general hygiene and may carry their own weaving equipment and thus reduce contact with infective agents on the hair dresser's hand [9]. Encouragement of personal hygiene has therefore become important in the prevention and control of this endemic disease.

Many of the children infected with T.capitis barb in public saloon in this study. Barbing saloon in Ilie are untidy and the practice of equipment sterilization was foreign to the operators of the four barbing saloon serving the village and the environment. David et al. [12] also demonstrated evidence of fungal element in barbing equipment in a recent study in Mubi, Adamawa state of Nigeria and suggested sensitization of public health workers and saloon customers on the need for sterilization of barbing equipment in all saloon. Ayanbimpe et al.[21] also attributed high incidence of $T$. capitis to continuous contact in barber's shop. With continuous and intense transmission of $T$. capitis, unless a bold step is taken to control the infection at the barber's shop, complete eradication of the condition might be a mirage.

This study demonstrated a non-significant positive correlation between duration of $T$. capitis and history of atopy. The commonest documented atopy condition was rhinitis. Hay and Shennan [22] and other workers [23] had previously reported association between the presence of atopy and chronic dermatophytosis, asthma and hay fever was the commonest atopic disease reported in their study. Other associations of chronic dermatophytosis include immediate- type hypersensitivity and elevated IgE levels which were not examined in this study.

In respect to the spectrum of isolated species of dermatophyte, it has been established that organism varies from one geographical location to another, even within a country, state, or local government area the patterns of isolates have varied overtime. In this study, the isolated dermatophytes were zoophylic, anthropophilic or geophilic. The organisms belonged to two general Trichophyton and Microsporon, and seven species which include T. metagrophyte, T.tonsurans, T.rubrum , M.audouinii, M.gypseum, T.violaceum, T.soudanens were isolated. The high prevalence of $T$. metagrophyte $(67.5 \%)$ in this study was similar to a recent finding by Nweke [13] in Anambra among normadic herdsmen living in camps. Jain et al. in Rajasthan district of India also found $T$. metagrophyte as the second leading agent in their study[24]. Jha et al. in eastern Nepal also found similar pattern [25]. This finding is not surprising because $166(89.7 \%)$ and $156(84.3 \%)$ of the children recruited into the study had history of unlimited contact with animals mainly goats and dogs. These animals, mainly live stocks have been kept for commercial purposes and almost all the households have their share in the livestock raring. The animals live in close contact with humans, direct contact is possible because animals are not been kept in special pen, and the children also participate in the raring of the animals. Animals have been variously implicated in Tinea transmission. This profile of isolate in this study was similar to findings of Ajao and Akintunde [9] but Microsporum aoduoinii was the leading agent in their study.

The finding of $T$. tonsurans, $T$. rubrum, $T$. soudanense, $T$. violaceous, $M$ gypseum is not strange in this environment. They have been isolated in various studies in Nigeria in the past as aetiological agent of $T$. capitis. $[3,4,8,10,11$, $12,13]$

It is worthy of note also, to comment on the high burden $42 / 179$ (23.5\%) of other nondermatophyte fungi infection of the children's scalp. Isolated in the study include: Penicillium spp, Blastomyces dermatidis, Candida albican, and Gliocladium spp. This is also not unusual because the children live in close contact with soil both at home and in the school. Oyeka and Ugwu had also noted that this non dermatophyte spores are uquibitous and may transiently colonized human skin [26]. The finding of this organism should be taken serious because isolates of non - dermatophyte was not found mixed with other dermatophyte organism, which will portend their isolation as been contaminants. More so, dermatophyte specific culture media (Potatoe agar) was used.

In this current study, the non- inflammatory $T$. capitis (GPTC; 46.5\%, BDTC; 42.2\%, and SDTC; 9.7\%), were more common than the inflammatory type (Pustular; 2.2\%). Previous findings also corroborated the fact that, gray patch T. capitis (GPTC) or black dot (BDTC) type are likely to be the leading clinical type in any epidemiologic survey $[20,27]$. The incidence of inflammatory type $(2.27 \%)$ is lower when compared with the findings of other authors [27,28] . Mixed morphology of T.capitis 
was rarely reported in literature [28]. There was no case of mixed morphology in this study. Several other studies confirmed the non inflammatory (GPTC or BDTC) to be the leading clinical types, and in some studies both almost occurred at the same proportion or frequency $[20,25,27,29]$. The inflammatory types of $\mathrm{T}$. capitis are uncommon in the present study. Nnoruka et al. [30] in Enugu state of Nigeria found a low incidence of kerion $(9,3.1 \%)$ in their study, while Grover et al. [27] in India found a higher incidence of inflammatory $T$. capitis at $32 \%$.

According to Gugnani and Najoku-Obi [3] the clinical appearance of T.capitis is most variable, and depends on the type of hair invasion, the level of host resistance and the degree of inflammatory host response. The ectothrix agent (T. metagrophyte) was prevalent in this study as a cause of the predominant non - inflammatory type, though not mutually exclusive for these clinical types alone in the study. The isolates of this study were mainly Trichophyton species that characteristically invaded the hair while producing large-spored ectothrix in chains as seen in T. mentagrophytes or the endothrix type as documented for T. tonsurans, T. soudanense, T. violaceum, $T$. yaoundei, $T$. gourvilii and rarely same may be demonstrated by $T$. rubrum. However, previous studies have shown that clinical presentation is not correctly indicative of the type of fungus or vice versa, as it also depends on other unknown factors [25,29], but Grover et al. in their study found endothrix agents to be responsible for BDTC and ectothrix agent to be responsible for GPTC, but the finding was not mutually exclusive also in their study. [27]

\section{CONCLUSIONS}

Tinea capitis remains an endemic disease reaching variable epidemic proportion in some populations as seen in Ilie among the children. The non - inflammatory type (GPTC, BDTC) were the prevalent clinical types of $T$. capitis in Ilie. Close animal and soil contact, poor sanitary condition at home, extreme of poverty were the most potent risk factors for contracting and sustaining the epidemic in this population. The cheapest means of prevention and controlling this infection depends on education of parent and sibling on reducing or preventing undue contact with the source of contagion.

\section{RECOMMENDATIONS}

The following are recommended:

1) Health education about infectious disease such T. capitis: including modes of transmission to the parents and children, and the importance of personal hygiene.

2) There is need for the establishment of community dermatological services to cater for the teeming needs of the children.

3) Since livestock keeping is a lifestyle of the Ilie people, I therefore suggest the need for construction of animal's pen by each household to reduce in- house contact with animals. This can be shouldered by the local health authority.

4) There is a need for effective community veterinary services for prompt treatment of infected animals.

5) Study of dermatophyte infections among animals in Ilie and its correlation with human dermatophytes is suggested as a future study.

Funding: This work was not funded by any agency.

Conflicts of interest: There are no conflicts of interest in the course of this research work.

Ethical approval : Ethical clearance was obtained from the ethical committee of Ladoke Akintola University Teaching hospital, Osogbo. Informed consents were obtained from parents of the children.

\section{REFERENCES}

1. Scott DW: Superficial Mycoses in Pederson D (Edn) Large animal Dermatology.publish by W.B Saunders company Harcort Brace jovanich Inc., 1988:172 - 175 .

2. Macura A B: Dermatophyte infection. int. $J$ of Dermatology 1993;32:313.

3. Gugnani HC, Njoku-Obi ANU. Tinea capitis in school children in East Nigeria. Mykosen 1986; 29: 132-144.

4. Anosike JC, Keke IR, Uwaezuoke JC, Anozie, J C, Obiukwu C, Nwoke B E B et al. Prevalence and distribution of ringworm infection in primary school children in parts of Eastern, Nigeria. $J$. of Appl. Sc. and Environ. Manag 2005; 9 (3): 21-25.

5. Fathi HI, Al-Samarai AG. Prevalence of tinea capitis among school children in Iraq. Eastern Mediterranean Health Journal 2000;06 (1):128 137.

6. Morar N, Dlova NC, Gupta AK, Aboobaker J. Tinea capitis in Kwa-Zulu Natal, South Africa. Paediatr Dermatol 2004; 21: 444 - 447. 
7. Shrank, AB. In A. B. Shrank and R. R. Harman. The incidence of skin diseases in a Nigerian teaching hospital dermatological clinic. Brit. J. Dermatol 1966; 78:239.

8. Soyinka F. Epidemiologic study of dermatophyte infections in Nigeria (Clinical Survey and Laboratory Investigations). Mycopathologia 1978; 63(2): 99-103.

9. Ajao AO, Akintunde CA. Studies on the prevalence of tinea capitis in Ile-Ife. Mycopathologia 2005;89: 43 - 48

10. Ogunbiyi A O, Owoaje E, Ndahi A. Prevalence of skin disorders in school children in Ibadan, Nigeria. Pediatric Dermatology 2005; 22: 6-10: 493- 498.

11. Enemuor C, Amedu AS. Prevalence of superficial mycoses in primary schoolchildren in Anyigba, Kogi State, Nigeria. African Journal of Microbiology Research 2009; 3 (2): 62-65.

12. David DL, Edward A, Zaruwa MZ, Addass PA. Barbing Saloon Associated Fungal Disease Infection in Mubi, Adamawa State-Nigeria. World J. Med. Sci.2010; 5 (1): 17- 21.

13. Nweke EI. Dermatophytosis among children of Fulani/Hausa herdsmen living in southeastern Nigeria. RevIberoam Micol.2010; 27(4):191- 194

14. Male $O$. The significance of mycology in medicine. In: Hawksworth DL (ed.), Frontiers in Mycology. Wallingford: $\mathrm{CAB}$ International, 1990: 131- 136.

15. Havlickova B, Czaika VA, Friedrich M. Epidemiological trends in skin mycoses worldwide. Mycoses 2004: 51 (4), 2-15.

16. Abdulkadir I. Dermatophytosis In: Infectious Diseases of livestock in Nigeria- An Outline. Pub Ahmadu Bello University Press Limited, Zaria,1989; 274- 275.

17. Ameh I.G , R.U Okolo. Dermatophytosis among children: Domestic animal as a predisposing factor in Sokoto, Nigeria. Pakistan Journal of Biological science 2004, 7 (7):1109 - 1112.

18. Macura A.B. Dermatophyte infection. Int $J$ Dermatol 1993; 32(5):313-323
19. Chineme, C.N, Adekeye J.O, Bida S.A. Trichophyton verrucossum in Young goat. Bull Hlth Prod Afr 1981 ; 29(1):75-78

20. Kalla G, Begra B, Solanki A, Goyal A, Batra A. Clinicomycological study of tinea capitis in desert district of Rajasthan, Ind $\mathbf{J}$ Dermatol Venereol Leprol 1995;6 : 342- 343.

21. Ayanbimpe GM, Taghir H, Diya A, Wapwera S. Tinea capitis among primary school children in some parts of central Nigeria. Mycoses 2008; 51, $336-340$.

22. Hay RJ, Shennan G. Chronic dermatophyte infections. II. Antibody and cell-mediate immune responses. Br J Dermatol 1982; 106: 191- 195.

23. Jones HE, Reinhardt JH, Rinaldi MG. Acquired immunity to dermatophytosis. Arch Dermatol 1974; 109: $840-848$.

24. Jain N, Sharma M, Saxena VN. Clinicomycological profile of dermatophytosis in Jaipur, Rajasthan. Indian J Dermatol Venereol Leprol 2008; 74 (3): 274- 275.

25. Jha BN, Garg VK, Agrawa S, Khanal B, Arun Agwalla A. Tinea capitis in eastern .Nepal Int J Dermatol 2006; 45 (2): 100 - 102.

26. Oyeka CA, Ugwu IO. Fungal flora of human toe webs. Mycoses 2002; 45:488 - 491.

27. Grover C, Arora P, Manchanda V. Tinea capitis in the pediatric population: A study from North India. Indian J Dermatol Venereol Leprol 2010; 76 (5): 527- 532.

28. Jahangir M, Hussain I, Khurshid K, Haroon TS. A clinico-etiologic correlation in Tinea capitis. Int J Dermatol 1999; 38: 275- 278.

29. Singal A, Rawat S, Bhattacharya S, Mohanty S, Baruah MC . Clinico- mycological profile of tinea capitis in North India and response to griseofulvin. J Dermatol 2001; 28: 22- 26.

30. Nnoruka EN, Ndu AN, Ohanu ME, Uzodimma BA, Udoh IP. Patchy hair loss in school children: Tinea capitis re-assessed. Journal of Pediatric Infectious Disease 2007; (3):147- 151. 